\title{
A Review: Advances in Draught Stress Tolerance in Wheat (Triticum aestivum L.)
}

\author{
P. N. Gaikwad ${ }^{1}$, G.S. Sidhu ${ }^{1}$, S. J. Gahukar ${ }^{2}$, S. J. Kharade ${ }^{3}$, \\ R. S. Chavan ${ }^{4}$, and P. N. Bhojane ${ }^{3}$
}

${ }^{1}$ School of Agricultural Biotechnology, Punjab Agriculture University, Ludhiana, Punjab, India (141004)

${ }^{2}$ College of Food Technology Yavatmal, Dr. Panjabrao Deshmukh krishi Vidyapeeth, Akola, Maharashtra, India (444104)

${ }^{3}$ Centre of Excellence in Plant Biotechnology, Dr. Panjabrao Deshmukh Krishi Vidyapeeth, Akola, Maharashtra, India (444104)

${ }^{4}$ Seed Technology Research Unit, Dr. Panjabrao Deshmukh krishi Vidyapeeth, Akola, Maharashtra, India (444104)

*Corresponding author

\section{A B S T R A C T}

\section{Keywords}

Water deficit, wheat, Genetic improvement, Draught, Physiological changes

\section{Article Info}

Accepted: 23 April 2020 Available Online: 10 May 2020
The major threat of the agricultural crop is the climate change, which grown globally in the subtropical and the tropical regions. Negative impact on the plant growth, development and the economic yield regarding climate change due to consequences of the draught stress. For the prediction of the climate change and occurrence of the draught many simulation models were recorded, it's very necessary to improve the crop against the draught stress which ultimately limits the production and the productivity of the crop. Wheat crop is widely used crop because of their social and the economic values. Many country around the world which depends on the wheat crop for food as well as feed and mainly wheat are the vulnerable against the draught stress. It's very challenging task to improve the draught stress of many researchers. The advances in the technology which ultimately gives understanding and the improvement in draught tolerance including the main three research areas viz., breeding, physiology and the genetics. When plants exposed to the draught stress the biochemical and the physiological pathways activated, the physiology focused on that research. In wheat, making the crosses through the breeding program which give the some high degree of the draught tolerance genotypes and also the many genes responsible for the draught tolerance which is identified by using the advanced biotechnological tools like QTL mapping, association mapping and GWAS technology for particular trait. In the past studies recorded, the draught tolerance shows the polygenic trait and its genetic constitution will helpful for the dissecting the gene network for controlling the draught tolerance. The presented review gives the recent advances in the main three research field for improvement of the draught tolerance in wheat. 


\section{Introduction}

The many crops grown all over world but the most important cereal crop is wheat (Triticum aestivum L.) and which grown in the rain fed area in which the draught causes prime role for the yield reduction (Rana et al., 2013). The occurrence of the draught stress is not only regionally but also globally widespread, which grows experimental formula encountered by the wheat plant and due to the so long time of water deficit stress lead to several minimize the overall production (Nezhadahmadi et al., 2013). Mainly the three factors like intensity, duration and the incidence time which determined draught stress. Due to variable conditions of the nature under draught stress is very complex for the breeder point of view for the improvement of the plant trait first to enhance the plant production (Mujtaba and Alam, 2002).

During the water stress given to plant at all stages of the plant growth affects the total grain yield but it has taken place in the critical stages of the growth which ultimately decreased grain yield sharply (Hanif et al., 2013, Zamurrad et al., 2013, Subhani et al., 2012). During reproductive stage, the crop yield reduced by the $70-80 \%$ due to draught stress reported (Kulkarni et al., 2008). Therefore, now a day it has important to develop the new better yield performing varieties, tolerant to the several climate condition to peculiar draught (Mahmood et al., 2013).

In the past decades, most of the researchers have reported draught tolerance in wheat and barley but unable to improvement of the crops against the draught tolerance limited for many reasons recorded. First, draught cause changes in the many physiological parameters of the plant in which needed measured and more understood. Second, genotype x environment interaction (GE) affects the selection procedure. Third, draught is very complex trait which is controlled by the many genes, which most makes the minor genetic contribution. Finally these are the important to improve genetically draught tolerance. Other factors also related to the complexity and the structure of wheat genome. Through the different technique draught stress studied to physiological, morphological, gene expression, breeding and genetic studies.

Some recently developed advance technique which related with the crop responses against biotic and abiotic stresses mainly water deficit stress is obtaining the significant impact, as globally fluctuation in the environmental conditions (Ullah et al., 2010). For better knowledge regarding draught stress tolerance with relation to physiological and morphological parameters helps in the characterization of germplasm for evaluation of genotypes against draught stress. One of the main superior aims of the plant breeders is the making of the wheat genotypes which suitable for the draught stress finally ensures the increases grain yield.

The field of the genomics results for wholegenome sequencing for the each and every genotypes possible. Researchers mostly and widely used technique is genotyping by sequencing, finally generates the single nucleotide polymorphism (SNP) marker that ultimately covers the whole genome of the wheat and barley (Hussain et al., 2017; Thabet et al., 2018). The reference genomes are available of wheat and barley. For identifying the correct position and location of the genes on the chromosome against the reference genome by using the SNP marker generated through genotype by sequencing technique. For the controlling the target traits by identifying the genes by using the genome wide association study (GWAS) and the Quantitative trait loci (QTL) through the 
implanting of the more number of SNPs used in the draught tolerance case. For measuring the traits depends on the number of genes identified which are associated with draught tolerance, proximity and magnitude of the gene. The many traits lead for the identification of the many genes controlling draught tolerance (Ovenden et al., 2017, Qaseem et al., 2018).

For draught gene such as Dreb and Fehw3 gene for specific molecular markers in draught stress (Rasheed et al., 2016). These two genes presence or absence can be tested for many germplasm, Draught tolerance, controlled by using the GWAS or QTL mapping through identifying the new genes (Zeng et al., 2014, Sukumaran et al., 2018). New era has been started by using the gene editing and genomic selection can be used to improve draught tolerance in the barley and wheat (Singh et al., 2015).

For mixing of the three broad research area including breeding, genetics and physiology with directly helps for identifying the draught tolerant genotypes which having the more number of genes control the draught tolerance in many conditions. This presented reviews gives the more explores the recently developed technique including the breeding, physiology and genetic research for enhancing the draught tolerance and the possible fates to identify the most promising draught tolerance plants for the further improvement of the trait.

\section{Draught and plant growth}

Draught is the most widespread environmental condition, severely diminish to the plant growth habit and crop production which are more than other environmental stresses (Edema et al., 2014, Rauf et al., 2007, Noorka et al., 2009, Shao et al., 2009). Draught stress often accumulates very slowly over the considerable time period which differs from the abiotic stress. Due to these characteristics of draught termed as "Creeping phenomena". As compared to the other natural stresses, its spread over very big geographical area relation to the greater damage. The situation is more serious regarding the climate change and draught worldwide spread problem eventually decreases the world crop production (Pan et $a l ., 2002)$. Out of all worlds agricultural land $25 \%$ land affected as the higher level of water stress (Jajarmi et al., 2002). Out of total wheat production $50 \%$ affects the draught stress (Pfeiffer et al., 2005). During grain filling stage in wheat crops shows draught in arid and semiarid regions. At the time of grain shriveling due to draught that time reduces yield. For the critical constraint to primary productivity in the arid climates, water limitation provides the critical role during the stages of the wheat production (Fischer et al., 2001). In arid areas draught supremacist is expected any plant growth critical stages (Hanif et al., 2013, Zamurrad et al., 2013, Subhani et al., 2012). Due to water shortage at the seedling and tillering ultimately poor crop growth and abnormal germination (Hasan et al., 2013, Noorka et al., 2007). At anthesis stage of growth which causes the maximum reduction yield in wheat crop (Akram et al., 2007).

\section{Physiological and biochemical responses}

In the past decades, many physiological and biochemical responses characterized in responses to the draught stress. Many physiological traits that show the effect of draught stress regarding growth and development of the wheat and barley plants. Many genes involved in the physiological changes governed by the plant are very prime role for the breeders and the field researchers, they used these genetic material for improve draught tolerance by breeding program. 


\section{Gaseous exchange and photosynthesis}

Photosynthesis is the primary role in the plant growth, development and economic grain yield. But for understanding the crop physiological responses during the draught is very critical at the water stress condition the photosynthesis determines by the use of photosynthetic pigment contents are the key factors which indicates the rate growth and development. In the cereals, during the draught which decreases the photosynthetic rates (Dawood et al., 2019). Improper imbalance between the light capture and utilization because of the metabolic photosynthetic activity distortion (Foyer et al., 2000), due to decrease in the Rubisco activity in the plant which ultimately loss of chloroplast membrane (Amirjani et al., 2013), chloroplast structure degradation and photosynthetic material, biosynthesis of chloroplast inhibition, chlorophyll substrate destruction, photo oxidation of chlorophyll and chrorophyllase activity increases (Kabiri et al., 2014). Stomatal limitations are much easier than the metabolic distortions which happened through the reduced form of the synthesis of the photosynthetic pigments (Rama et al., 2014). The responses of the draught decreases by the mesophyll and stomatal conductance to the $\mathrm{CO}_{2}$ (Centritto et al., 2009). For the conserve water status during the draught stress the stomatal closure which minimizes the transpirational water loss from the plant. Due to stomata closure decreases $\mathrm{CO}_{2}$ for photosynthetic metabolism, $\mathrm{CO}_{2}$ assimilation decreases which ultimately prohibits the dry matter accumulation of plant ability (A. et al., 2003). Draught stress affect the chlorophyll pigment which deferentially depends on the genotype or species studied. Chlorophyll content affected by the genetic variation. Under the water stress conditions high chlorophyll contents gives the more seed yield (Alaei et al., 2011). Chlorophyll content, number of grains per spike and grain filling period are positively correlated with the grain yield in wheat were recorded (Kilic et al., 2010).

\section{Water relation}

The plant water relation are influenced by the some prime characteristics like water loss rate, relative water content, water content, succulence index, residual transpiration rate and excised leaf water retention. Plant water status is measured by Relative Water Content (RWC), tissue reflects the metabolic activity and this index noted for the dehydration tolerance. Due to the draught stress noted many varieties of plants decreases their relative water content (Allahverdiyev et al., 2015). Under the draught stress the leaf water potential was negatively correlated with the grain yield of barley (Samarah et al., 2009). In draught stress grain yield and water content are significantly positive correlation at the time of reproductive stages in the barley and wheat. Therefore, improvement of draught tolerance through breeding programs in the high yield combination with the use of relative water content and leaf rolling (Tahara et al., 1990, Teulat et al., 1997).

\section{Nutrient relation}

Soil water content decreases, also decrease in the radius of the water filled pores, increases tortusosity and the decreases in the mobility of the $\mathrm{P}$ (Faye et al., 2006). P uptake reduces due to the decline availability of the $\mathrm{P}$ and foliar content of the $\mathrm{P}$ reduces consequently (Sardans et al., 2004). Cations like $\mathrm{K}^{+}, \mathrm{Ca}^{2+}$, $\mathrm{Mg}^{2+}$ (membrane permeability and the active transport) reduces during draught stress, and finally absorption of the cations through roots decreased (Farooq et al., 2012). On the above ground biomass the $\mathrm{Ca}^{2+}$ concentration decreases in the draught stress and this resulting the gradually transpiration flux reduction (Sardans et al., 2008). In wheat 
plant during the water stress in the root and shoot the level of phosphorus, calcium and potassium reduced and this result recorded by the (Noman et al., 2018). In the draught stress some micronutrients viz., Mo, Mn and Fe can be induced (Hu et al., 2005). In the well water conditions micronutrients are more available because of their soluble and reduced uptake form (Havlin et al., 1999).

\section{Hormonal effect}

Abscisic acid production affect during draught stress adaptation by avoidance of dehydration and the tolerance dehydration (Thomposon et al., 2007). Many hormones regulating the tolerance mainly $\mathrm{ABA}$ against abiotic stresses like heat, cold, wounding and draught (Lata et al., 2011). ABA has been identified as a stress signal from root to shoot (Schachtman et al., 2018), contains the leaf expansion inhibition and the responses in the short term as a stomatal closure. ABA gives the systemic responses against the abiotic stress, before its detectable changes in terms of the nutrient status and the leaf water (Suzuki et al., 2013). Moreover, the ABA reported as enhancer for the root growth and development in the wheat and significantly correlated with the grain yield under the draught stress (Xu et al., 2013).

\section{Breeding approaches against draught stress}

Now a day, new technique developed after the DNA sequencing which provides the high density marker technology by using the single nucleotide polymorphism (SNP) markers (Eltaher et al., 2018). Genotyping by sequencing is one of the most prime sequencing methods and it gives the number of SNPs that coverage total genome of wheat and barley. In targeting the essential genes which controlling the draught stress tolerance in the wheat and barley by using the combination of the traditional breeding and advanced DNA sequencing technology (Hussain et al., 2017; Sukumaran et al., 2018; Reinert et al., 2016; Mwadzingeni et al., 2017).

\section{Genetic variation at different growth stages}

\section{Germination stage}

The series of events is happened during the seed germination and it's usually starts with the water imbibition in the seeds, further its convert to emerge radical from the seed coat (Srivastava et al., 2003). It's very sensitive stages during draught stress, reduces the seed germination percentage and the emergence of the seedlings in the wheat and barley crop. For example many farmers in the India and Pakistan, the rainfed area totally depend on the coming monsoon (Kerr et al., 2019). For induction of the draught stress there are so many various concentration of PEG solution, due to responses gives at different concentration that why it's essential to for testing the different rage of concentration (Kido et al., 2016). Due to the high weight of PEG (6000 or $8000 \mathrm{KDa}$ ) which inhibits the cell wall from penetrating the water. Due to that reason PEG mostly used for controlling the water potential at the germination stage (Khazayi et al., 2008).

\section{Seedling stage}

At the seedling stage, seedling stage comes after the seed germination stage, when the plants developed the cannabis leaves traditionally. Seedling stage is also been the critical stage when the moisture stress are present surroundings. For evaluating the draught tolerance during the seedling stage is primary role and which ultimately affects the upcoming stages and finally total grain yield (Gallagher et al., 1976). After experienced in the genetic variation at seedling stage, which 
eventually increases the possibility of the draught tolerant varieties during the breeding selection program (Hameed et al., 2010).

Improvement of draught tolerance in wheat by high throughput phenotyping

Using the newly developed technology that is High Throughput Phenotyping (HPP) which rapidly screen the thousands of genotypes for many desired trait of interest. The high automated facility is needed for this technology in the growth chamber or the greenhouses with controlled environmental condition, with accurate sensing technology is essential and also robotics (Araus et al., 2014) or phenocarts in the field. By using HPP regarding the particular trait of interest through the screening of the thousands of the genotypes which improves the breeding process more precisely because its evaluate the previously unavailable and useful data in the draught stress viz., plant water status, leaf temperature and predicted level of yield (Winterhalter et al., 2013). For the estimation of the plant parameters and the different vegetation indices by using these platform mainly including passive and spectral sensors (Erdle et al., 2011, Hackl et al., 2012).

\section{Draught tolerance improvement by using nanotechnology}

In recent decades, many plant researchers shows their interest in the nanotechnology related to the agriculture, which by applying the nanoparticles (NP) and some beneficial effects were recorded by many researchers in relation to the enhancing the agricultural production and tolerance against the biotic and abiotic stresses (Jsarotia et al., 2018). Many advantages of nanotechnology regarding agriculture were recorded out of them cheap, low phytotoxicity and cheap (Taran et al., 2017) and nanoparticles work as a positive or negative biological effects on the basis of their concentration (Olkhovych et al., 2016). For improving the yield components by the application of $\mathrm{SiO}_{2}$ under the draught stress, $\mathrm{TiO}_{2}$ at some concentration gives decreased seed yield (Ghorbanian et al., 2019).

\section{Genetic basis of draught tolerance in wheat}

By using the molecular markers and genome sequencing in the wheat and barley which provides genetic analysis studies of the draught tolerance. Such genetic analysis containing the many approaches like association mapping QTL mapping genome wide analyses and transcriptome expression analysis goals to characterize and detection of particular gene to draught stress adaptation (Hu et al., 2014).

\section{QTL for draught tolerance}

So many prime genomic regions have been recorded by many researchers through the QTL mapping tool. These researches are helped to identify the regions underlying the difference of the draught tolerance traits and the genetic factor of the mixed trait in the wheat and barley. For the evaluation of the genotypic performance commonly used multi environmental conditions are necessary (Mathews et al., 2008, Von et al., 2008) using various type of population like recombinant inbred line (RIL) population (Mathews et al., 2008, Von et al., 2008, Maccaferri et al., 2008, McIntyre et al., 2010) specially bi parental population, doubled haploid (DH) population (Quarrie et al., 1994, Obsa et al., 2016) and advanced backcross (Kalladan et al., 2013). For identifying the QTL and population genotyping various molecular markers like Restriction Fragment Length Polymorphism (RFLP), Simple Sequence Repeats (SSR), Amplified Fragment Length Polymorphism (AFLP) (Maccaferri et al., 2008, Quarrie et al., 1994) and Single 
Nucleotide Polymorphism (SNP) (Kalladan et al., 2013). Now a day's population genotyping through the genetic SNP with the high density marker were carried out (Obsa et al., 2016).

\section{Analysis of draught tolerance through the genomics}

By using the huge number of SNPs that ultimately generates the high density linkage map through the GWAS approaches and to identify the gene on the whole chromosome can also be detected whereas GWAS study used both diverse population as well as the biparental population. The biggest strength of the GWAS to detect the novel regions and regions for the draught stress tolerance in wheat and barley. For example, GWAS recorded QTLs regarding the yield components in the 208 varieties of durum wheat with the use of 6211 SNPs (Sukumaran et al., 2018), by using the 16383 DArTs 93 bread wheat genotypes (Mwadzingeni et al., 2017), 123 wheat cultivar through $90 \mathrm{k}$ SNP array (Ain et al., 2015). Diverse collection and the marker type which detect the genomic regions associated with the grain yield and related traits significantly (Mobasser et al., 2017, Faye et al., 2006, Sardans et al., 2004). Candidate gene and the genetic architecture of the draught stress tolerance and related traits mainly root, yield and leaf were predicted by the use of 108 bread wheat and 9646 SNPs (Qaseem et al., 2018) and 20881 SNPs using the 200 bread wheat genotypes (Beyer et al., 2019).

In conclusion, water stress is so important to detect the genomic responses. Firstly, transcriptional reaction prepares the more information of the plants to draught stress. Secondly, during the stress environment it's possible to understand the genes and their functions. Thirdly, more important to differ the promoter's reacts during the stress and their related cis elements, which are both very primitive studies in the crop engineering (Zhou et al., 2007). For fast improvement against the draught resistance by using the manipulation of genes responsible for the antioxidants, proteins, transcriptional factors and plant growth regulators (Gupta et al., 1999). Molecular mapping and the QTL mapping are also most efficient methods for detecting the qualitative and quantitative characters mainly in the resistance against the stress. But also the some limitation of this methods that is inconsistent repeatability, interaction between the environment and the genotypes QTL detection for the instance, numerous genes that's regulating the yield and wrong mapping population used. Other limitation of the QTL like improper interaction epistasis, to extract the substance to carry the alleles influences its difficult (Collins et al., 2008, Podlich et al., 2004). Moreover, in the many circumstances, the QTL does not show marked impact; even stop in various ground work, even also the same growth conditions (Collins et al., 2008, Cho et al., 2006). Due to this high changeable in the nature of the water stress and the less information of the complexness have caused, and eventually it's hard to identify the particular physiological traits necessary for improved the crop performance.

\section{Acknowledgment}

All authors grateful to acknowledge and thanks for the institution provided kindly help during the written of review and all colleagues for their valuable guidance and support.

\section{References}

A, M.M.C., B, J.P.M., A, J.S.P. Understanding plant responses to drought- from genes to the whole plant. Funct. plant biol. 2003, 239-264.

Ain, Q.U., Rasheed, A., Anwar, A., Mahmood, 
T., Imtiaz, M., Mahmood, T., Xia, X., He, Z., Quraishi, U.M. Genome-wide association for grain yield under rainfed conditions in historical wheat cultivars from Pakistan. Front. Plant Sci., 2015, 6, 743.

Akram M. Growth and yield components of wheat under water stress of different growth stages. Bangladesh J. Agric. Res. 2011; 36: 455-468.

Alaei, Y. The Effect of Amino Acids on Leaf Chlorophyll Content in Bread Wheat Genotypes under Drought Stress Conditions. Middle-East J. Sci. Res. 2011, $10,99-101$.

Allahverdiyev, T.I. Effect of drought stress on some physiological parameters, yield, yield components of durum (Triticum durum desf.) and bread (Triticum aestivum L.) wheat genotypes. Ekin J. Crop Breed. Genet. 2015, 1, 50-62.

Amirjani, M.R., Mahdiyeh, M. Antioxidative and biochemical responses of wheat. $\mathrm{J}$. Agric. Biol. Sci2013, 8, 291-301.

Araus, J.L., Cairns, J.E. Field high-throughput phenotyping: the new crop breeding frontier. Trends Plant Sci2014, 19, 52-61.

Beyer, S., Daba, S., Tyagi, P., Bockelman, H., Brown-Guedira, G., Mohammadi, M. Loci and candidate genes controlling root traits in wheat seedlings-a wheat root GWAS. Funct. Integr. Genomics 2019, 19, 91-107.

Centritto, M., Lauteri, M., Monteverdi, M.C., Serraj, R. Leaf gas exchange, carbon isotope discrimination, and grain yield in contrasting rice genotypes subjected to water deficits during the reproductive stage. J. Exp. Bot. 2009, 60, 2325-2339.

Cho E. K. and C. B. Hong, "Over-expression of tobacco NtHSP70-1 contributes to droughtstress tolerance in plants," Plant Cell Reports, vol. 25, no. 4, pp. 349-358, 2006.

Collins, N. C., F. Tardieu, and R. Tuberosa, "Quantitative trait loci and crop performance under abiotic stress: where do we stand?" Plant Physiology, vol. 147, no. 2, pp. 469-486, 2008.

Dawood, M.F.A., Abeed, A.H.A., Aldaby, E.E.S. Titanium dioxide nanoparticles model growth kinetic traits of some wheat cultivars under di_erent water regimes. Indian J. Plant Physiol. 2019, 24, 129-140.

Edema NE. Effects of Climate Change Critical Factors on the Seedling Growth and Development of Maize (Zea mays L.). Americ. J. Exp. Agri. 2014; 4(12): 16491657.

Eltaher, S., Sallam, A., Belamkar, V., Emara, H.A., Nower, A.A., Salem, K.F.M., Poland, J., Baenziger, P.S. Genetic Diversity and Population Structure of F3:6 Nebraska Winter Wheat Genotypes Using Genotyping-By-Sequencing. Front. Genet. 2018, 9, 76.

Farooq, M., Hussain, M., Wahid, A., Siddique, K.H.M. Plant Responses to Drought Stress; Springer: Berlin/Heidelberg, Germany, 2012; pp. 1-6.

Faye, I., Diouf, O., Guisse, A., Sene, M., Diallo, $\mathrm{N}$. Characterizing root responses to low phosphorus in pearl millet [Pennisetum glaucum (L.) R. Br.]. Agron. J. 2006, 98, 1187-1194.

Fischer G, Shah M, Velthuizen HV, Nachtergaele FO. Global agro-ecological assessment for agriculture in the $21^{\text {st }}$ Century. IIASA Research Report 02-02, Int. Inst. Appl. Systems Analysis, Laxenburg, Austria. 2001;119.

Foyer, C.H. Bundle sheath proteins are more sensitive to oxidative damage than those of the mesophyll in maize leaves exposed to paraquat or low temperatures. J. Exp. Bot. 2000, 51, 123-130.

Gallagher, J.N., Biscoe, P.V., Hunter, B. Effects of drought on grain growth. Nature 1976, 264, 541-542.

Ghorbanian, H., Janmohammadi, M., EbadiSegherloo, A., Sabaghnia, N. Genotypic response of barley to exogenous application of nanoparticles under water stress condition. Ann. Univ. Mariae CurieSklodowska, Sect. C - Biol. 2019, 72, 1527.

Gupta, P.K., R. K. Varshney, P. C. Sharma, and B. Ramesh, "Molecular markers and their applications in wheat breeding," Plant Breeding, vol. 118, no. 5, pp. 369-390, 
1999.

Hackl, H., Baresel, J.P., Mistele, B., Hu, Y., Schmidhalter, U. A Comparison of Plant Temperatures as Measured by Thermal Imaging and Infrared Thermometry. J. Agron. Crop Sci., 2012, 198, 415-429.

Hameed, A., Goher, M., Iqbal, N. Evaluation of Seedling Survivability and Growth Response as SelectionCriteria for Breeding Drought Tolerance in Wheat. Cereal Res. Commun. 2010, 38, 193-202.

Hanif R, Naeem-ud-Din, Subhani A, Rabbani G, Tariq M, Iqbal MS, Koukab M. Performance based evaluation of different genotypes of Mungbean (Vigna radiata) under rainfed conditions of Chakwal. J. Agri. Food Appl. Sci. 2013; 1: 13-15.

Hasan MA, Ahmed JU, Hossain T, Mian MAK, Haque MM. Evaluation of the physiological quality of wheat seed as influenced by high parent plant growth temperature. J. Crop Sci. Biotech.2013;16: 69-74.

Havlin, J. Soil Fertility and Fertilizers: An Introduction to Nutrient Management, 6th ed., Prentice Hall: Upper Saddle River, NJ, USA, 1999; ISBN 0136268064.

$\mathrm{Hu}, \mathrm{H}$., Xiong, L. Genetic engineering and breeding of drought-resistant crops. Annu. Rev. Plant Biol. 2014, 65, 715-741.

$\mathrm{Hu}, \mathrm{Y}$., Schmidhalter, U. Drought and salinity: A comparison of their effects on mineral nutrition of plants. J. Plant Nutr. Soil Sci. 2005, 168, 541-549.

Hussain, W., Stephen Baenziger, P., Belamkar, V., Guttieri, M.J.M.J., Venegas, J.P.J.P., Easterly, A., Sallam, A., Poland, J. Genotyping-by-Sequencing Derived HighDensity Linkage Map and its Application to QTL Mapping of Flag Leaf Traits in Bread Wheat. Sci. Rep. 2017, 7, 16394.

Jajarmi V. Effect of water stress on germination indices in seven wheat cultivar. World Acad. Sci. Eng. Technol. 2002; 49: 105106.

Jsarotia, P., Kashyap, P.L., Bhardwaj, A.K., Kumar, S., Singh, G.P. Nanotechnology Scope and Applications for Wheat Production and Quality Enhancement: A
Review of Recent Advances. Wheat Barley Res. 2018, 10, 137-150.

Kabiri, R., Nasibi, F., Farahbakhsh, H. Effect of Exogenous Salicylic Acid on Some Physiological Parameters and Alleviation of Drought Stress in Nigella sativa Plant under Hydroponic Culture. Plant Prot. 2014, 50, 43-51.

Kalladan, R., Worch, S., Rolletschek, H., Harshavardhan, V.T., Kuntze, L., Seiler, C., Sreenivasulu, N., Roder, M.S. Identification of quantitative trait loci contributing to yield and seed quality parameters under terminal drought in barley advanced backcross lines. Mol. Breed. 2013, 32, 71-90.

Kerr, J.M. Sustainable Development of Rainfed Agriculture in India. Available online: https://ageconsearch.

umn.edu/record/16104/ (accessed on 20 May 2019).

Khazayi, H., Kafi, M., Masumi, A. Physiological effects of stress induced by polyethylene glycol on germination of chickpea genotypes. J. Agron. Res. Iran 2008, 2, 453.

Kido, É.A., Ferreira-Neto, J.R.C., Pandolfi, V., de Melo Souza, A.C., Benko-Iseppon, A.M. Drought Stress Tolerance in Plants: Insights from Transcriptomic Studies. In Drought Stress Tolerance in Plants, Vol 2; Springer: Cham, Switzerland, 2016; pp. 153-185.

Kiliç, H., Ya gbasanlar, T. The effect of Drought Stress on Grain Yield, Yield Components and some Quality Traits of Durum Wheat (Triticum turgidum ssp. durum). Cultivars 2010, 38, 164-170.

KulKarni M, Borse T, Czech SC. Mining anatomical traits: A novel modelling approach for increased water use efficiency under drought conditions in plants. $\mathrm{J}$. Genet. Plant Breed. 2008; 44: 11- 21.

Lata, C., Prasad, M. Role of DREBs in regulation of abiotic stress responses in plants. J. Exp. Bot. 2011, 62, 4731-4748.

Maccaferri, M., Sanguineti, M.C., Corneti, S., Ortega, J.L.A., Salem, M.B., Bort, J., DeAmbrogio, E., del Moral, L.F.G., 
Demontis, A., El-Ahmed, A., et al., Quantitative Trait Loci for Grain Yield and Adaptation of Durum Wheat (Triticum durum Desf.) Across a Wide Range of Water Availability. Genetics 2008, 178, 489-511.

Mahmood A, Mian MA, Ihsan M, Ijaz M, Rabbani G, Iqbal MS. Chakwal-50: A high yielding and disease resistant wheat variety for rainfed region. J. Anim. Plant Sci. 2013; 23:833-839.

Mathews, K.L., Malosetti, M., Chapman, S., McIntyre, L., Reynolds, M., Shorter, R., van Eeuwijk, F. Multi-environment QTL mixed models for drought stress adaptation in wheat. Theor. Appl. Genet. 2008, 117, 1077-1091.

McIntyre, C.L., Mathews, K.L., Rattey, A., Chapman, S.C., Drenth, J., Ghaderi, M., Reynolds, M., Shorter, R. Molecular detection of genomic regions associated with grain yield and yield-related components in an elite bread wheat cross evaluated under irrigated and rainfed conditions. Theor. Appl. Genet. 2010, 120, 527-541.

Mobasser, H.R., Mohammadi, G.N., Abad, H.H.S., Rigi, K. Effect of application elements, water stress and variety on nutrients of grain wheat in Zahak region, Iran. JBES 2014, 5, 105-110.

Mujtaba S and Alam S (2002) Drought phenomenon and crop growth. Pakistan leading magazine for the last pp. 25.

Mwadzingeni, L., Shimelis, H., Rees, D.J.G., Tsilo, T.J. Genome-wide association analysis of agronomic traits in wheat under drought-stressed and non-stressed conditions. PLoS ONE 2017, 12, e0171692.

Mwadzingeni, L., Shimelis, H., Rees, D.J.G., Tsilo, T.J. Genome-wide association analysis of agronomic traits in wheat under drought-stressed and non-stressed conditions. PLoS ONE 2017, 12, e0171692.

Nezhadahmadi A, Prodhan Z and Faruq G (2013) Drought Tolerance in Wheat. The Scientific World Journal 13: 1-12.
Noman, A., Ali, Q., Naseem, J., Javed, M.T., Kanwal, H., Islam, W., Aqeel, M., Khalid, N., Zafar, S., Tayyeb, M., et al., Sugar beet extract acts as a natural bio-stimulant for physio-biochemical attributes in water stressed wheat (Triticum aestivum L.). Acta Physiol. Plant. 2018, 40, 110.

Noorka IR, Khaliq I, Akram Z, Iqbal MS. Inheritance studies of physio-genetic traits in spring wheat under normal and moisture stress environments. Int. J. Agri. Appl. Sci. 2009; 1: 29-34.

Noorka IR, Khaliq I. An efficient technique for screening wheat (Triticum aestivum L.) germplasm for drought tolerance. Pak. J. Bot. 2007; 39: 1539-1546.

Obsa, B.T., Eglinton, J., Coventry, S., March, T., Langridge, P., Fleury, D. Genetic analysis of developmental and adaptive traits in three doubled haploid populations of barley (Hordeum vulgare L.). Theor. Appl. Genet. 2016, 129, 1139-1151.

Olkhovych, O., Volkogon, M., Taran, N., Batsmanova, L., Kravchenko, I. The Effect of Copper And Zinc Nanoparticles on the Growth Parameters, Contents of Ascorbic Acid, and Qualitative Composition of Amino Acids and Acylcarnitines in Pistias tratiotes L. (Araceae). Nanoscale Res. Lett. 2016, 11, 218.

Ovenden, B., Milgate, A., Wade, L.J., Rebetzke, G.J., Holland, J.B. GenomeWide Associations for Water-Soluble Carbohydrate Concentration and Relative Maturity in Wheat Using SNP and DArT Marker Arrays. G3 2017, 7, 2821-2830.

Pan XY, Wang YF, Wang GX, Cao QD, Wang J. Relationship between growth redundancy and size inequality in spring wheat populations mulched with clear plastic film. Acta Phytoecol. Sinica. 2002; 26: 177-184.

Pfeiffer WH, Trethowan RM, Van Ginkel M, Ortiz MI, Rajaram S. Breeding for abiotic stress tolerance in wheat. In abiotic stresses: plant resistance through breeding and molecular approaches (eds. Ashraf, M. and P.J.C. Harris), The Haworth Press, New York, NY, USA. 2005; Pp. 401-489. 
Podlich, D. W., C. R. Winkler, and M. Cooper, "Mapping as you go: an effective approach for marker-assisted selection of complex traits," Crop Science, vol. 44, no. 5, pp. 1560-1571, 2004.

Qaseem, M.F., Qureshi, R., Muqaddasi, Q.H., Shaheen, H., Kousar, R., Röder, M.S. Genome-wide association mapping in bread wheat subjected to independent and combined high temperature and drought stress. PLoS One 2018, 13, e0199121.

Quarrie, S., Gulli, M., Calestani, C., Steed, A., Marmiroli, N. Location of a gene regulating drought-induced abscisic acid production on the long arm of chromosome 5A of wheat. Theor. Appl. Genet. 1994, 89, 794-800.

Rama, R., Nagaraja, R., Ragimasalawada, M., Sabbavarapu, M.M., Nadoor, S., Patil, J.V. Detection and validation of stay-green QTL in post-rainy sorghum involving widely adapted cultivar, M35-1 and a popular stay-green genotype B35. BMC Genomics 2014, 15, 909.

Rana RM, Rehman S, Ahmed J and Bilal M (2013) A comprehensive overview of recent advances in drought stress tolerance research in wheat (Triticum aestivum L.). Asian Journal of Agriculture and Biology 1: 29-37.

Rasheed, A., Wen, W., Gao, F., Zhai, S., Jin, H., Liu, J., Guo, Q., Zhang, Y., Dreisigacker, S., Xia, X., et al., Development and validation of KASP assays for genes underpinning key economic traits in bread wheat. Theor. Appl. Genet. 2016, 129, 1843-1860.

Rauf M, Munir M, Hassan M, Ahmed M, Afzai M. Performance of wheat genotypes under osmotic stress at germination and early seedling growth stage. Afric. J. Biotech. 2007; 8: 971-975.

Reinert, S., Kortz, A., Léon, J., Naz, A.A. Genome-Wide Association Mapping in the Global Diversity Set Reveals New QTL Controlling Root System and Related Shoot Variation in Barley. Front. Plant Sci. 2016, 7, 1061.

Samarah, N.H., Alqudah, A.M., Amayreh, J.A.,
McAndrews, G.M. The Effect of Lateterminal Drought Stress on Yield Components of Four Barley Cultivars. J. Agron. Crop Sci. 2009, 195, 427-441.

Sardans, J., Peñuelas, J. Increasing drought decreases phosphorus availability in an evergreen Mediterranean forest. Plant Soil 2004, 267, 367-377.

Sardans, J., Peñuelas, J., Ogaya, R. Drought's impact on $\mathrm{Ca}, \mathrm{Fe}, \mathrm{Mg}, \mathrm{Mo}$ and $\mathrm{S}$ concentration and accumulation patterns in the plants and soil of a Mediterranean evergreen Quercus ilex forest. Biogeochemistry 2008, 87, 49-69.

Schachtman, D.P., Goodger, J.Q. Chemical root to shoot signaling under drought. Trends Plant sci. 2018, 13, 281-287.

Shao HB, Chu LY, Jaleel CA, Manivannan P, Panneerselvam P, Shao MA. Understanding water deficit stress-induced changes in the basic metabolism of higher plants-biotechnologically and sustainably improving agriculture and the eco environment in arid regions of the globe. Crit. Rev. Biotech. 2009;29:131-151.

Singh, A.K.S.B.D. Marker-Assisted Plant Breeding: Principles and Practices, 1st ed., Springer India: Delhi, India, 2015; ISBN 978-81-322-2316-0.

Srivastava, L.M. Plant growth and development: hormones and environment. Ann Bot. 2003, 92, 846.

Subhani A, Tariq M, Jafar MS, Latif R, Khan M, Iqbal MS, Iqbal MS, Role of soil moisture in fertilizer use efficiency for rainfed areas-a review. J. Bio. Agri. Healthcare. 2012; 2: 1-9.

Sukumaran, S., Reynolds, M.P., Sansaloni, C. Genome-Wide Association Analyses Identify QTL Hotspots for Yield and Component Traits in Durum Wheat Grown under Yield Potential, Drought, and Heat Stress Environments. Front. Plant Sci., 2018, 9, 81 .

Suzuki, N., Miller, G., Salazar, C., Mondal, H.A., Shulaev, E., Cortes, D.F., .Shuman, J.L., Luo, X., Shah, J., Schlauch, K., et al., Temporal-spatial interaction between reactive oxygen species and abscisic acid 
regulates rapid systemic acclimation in plants. Plant Cell 2013, 25, 3553-3569.

Tahara, M., Carver, B.F., Johnson, R.C., Smith, E.L. Relationship between relative water content during reproductive development and winter wheat grain yield. Euphytica1990, 49, 255-262.

Taran, N., Storozhenko, V., Svietlova, N., Batsmanova, L., Shvartau, V., Kovalenko, M. Effect of Zinc and Copper Nanoparticles on Drought Resistance of Wheat Seedlings. Nanoscale Res. Lett. 2017, 12, 60.

Teulat, B., Monneveux, P., Wery, J., Borries, C., Souyris, I., Charrier, A., This, D. Relationships between relative water content and growth parameters under water stress in barley: a QTL study. New Phytol. 1997, 137, 99-107.

Thabet, S.G., Moursi, Y.S., Karam, M.A., Graner, A., Alqudah, A.M. Genetic basis of drought tolerance during seed germination in barley. PLoS ONE 2018, 13, e0206682.

Thompson, A.J., Andrews, J., Mulholland, B.J., McKee, J.M.T., Hilton, H.W., Black, C.R., Taylor, I.B. Overproduction of abscisic acid in tomato increases transpiration e_ciency and root hydraulic conductivity and influences leaf expansion. Plant Physiol. 2007, 143, 1905-1917.

Ullah N, Shafi M, Akmal M and Hassan G (2010) In situ assessment of morphophysiological response of wheat (Triticum aestivum L.) genotypes to drought. Pakistan Journal of Botany 42: 31833195.

Von Kor_, M., Grando, S., Del Greco, A., This,
D., Baum, M., Ceccarelli, S. Quantitative trait loci associated with adaptation to Mediterranean dryland conditions in barley. Theor. Appl. Genet. 2008, 117, 653-669.

Winterhalter, L., Mistele, B., Schmidhalter, U. Evaluation of active and passive sensor systems in the field to phenotype maize hybrids with high-throughput. F. Crop. Res. 2013, 154, 236-245. Erdle, K., Mistele, B., Schmidhalter, U. Comparison of active and passive spectral sensors in discriminating biomass parameters and nitrogen status in wheat cultivars. F. Crop. Res. 2011, 124, 74-84.

Xu, W., Jia, L., Shi, W., Liang, J., Zhou, F., Li, Q., Zhang, J. Abscisic acid accumulation modulates auxin transport in the root tip to enhance proton secretion for maintaining root growth under moderate water stress. New Phytol. 2013, 197, 139-150.

Zamurrad M, Tariq M, Shah FH, Subhani A, Ijaz M, Iqbal MS, Koukab M. Performance based evaluation of groundnut genotypes under medium rainfall conditions of Chakwal. J. Agri. Food Appl. Sci. 2013;1:9-12.

Zeng, Z.B., Teulat, B., Merah, O., Sirault, X., Borries, C., Waugh, R., This, D., Abebe, T., Guenzi, A.C., Martin, B., et al., Detection and validation of novel QTL for shoot and root traits in barley (Hordeum vulgare L.). J. Exp. Bot. 2014, 9, 171-180.

Zhou, J. X. Wang, Y. Jiao "Global genome expression analysis of rice in response to drought and high-salinity stresses in shoot, flag leaf, and panicle," Plant Molecular Biology, vol. 63, no. 5, pp. 591-608, 2007.

\section{How to cite this article:}

Gaikwad, P. N., G.S. Sidhu, S. J. Gahukar, S. J. Kharade, R. S. Chavan and Bhojane, P. N. 2020. A Review: Advances in Draught Stress Tolerance in Wheat (Triticum aestivum L.). Int.J.Curr.Microbiol.App.Sci. 9(05): 2873-2884. doi: https://doi.org/10.20546/ijcmas.2020.905.330 